\title{
Launching a statewide Employment First initiative: Indiana's work to include coalition
}

\author{
Patricia Rogan* and Susan Rinne \\ IUPUI School of Education, Work to Include Coalition, Indianapolis, IN, USA
}

Received 30 November 2020

Accepted 30 November 2020

\begin{abstract}
.
BACKGROUND: After decades of local, state and national efforts to increase employment outcomes for individuals with disabilities, progress has been slow, with a mere $17.9 \%$ of persons with a disability employed in 2020 compared to $61.8 \%$ for persons without a disability (U.S. Bureau of Labor Statistics, February 2021). Individuals with disabilities have demonstrated their abilities and desire to work, including those with significant disabilities, yet our country remains entrenched in outdated and ineffective models of day services (i.e., sheltered workshops, non-work programs) and precious public dollars continue to be used for these services that congregate and segregate individuals, pay subminimum wages, and deny individuals their human and civil rights.

OBJECTIVE: The purpose of this article is to describe one state's efforts to advance employment for working age individuals with disabilities through a statewide Employment First initiative called Work to Include. Indiana is now in its third year of this grassroots initiative driven by a coalition of self-advocates. Major activities of the initiative are discussed, including passing Indiana's Employment First law, holding statewide Town Hall meetings, establishing 11 local Work to Include teams, developing and implementing a state Employment First plan, launching local and statewide Disability Employment Awareness month campaigns, using social media and webinars to disseminate information, hosting Employment First Summits, and collaborating with employers and state agencies to promote employment outcomes.
\end{abstract}

CONCLUSION: Next steps toward systems change are discussed, including the establishment of an Employment First office at the state and securing an Executive Order from the governor to make the state a model employer.

Keywords: Employment First, employment of people with disabilities, state systems change

\section{Introduction}

After decades of local, state and national efforts to increase employment outcomes for individuals with disabilities, progress has been slow. According to

*Address for correspondence: Patricia Rogan, Ph.D., Professor, School of Education, Indiana University-Purdue University, Indianapolis (IUPUI), IN, USA. Tel.: +1 317274 6861; E-mail: progan@iupui.edu. the U.S. Bureau of Labor Statistics, 17.9 percent of persons with a disability were employed in 2020 compared to the employment-population ratio for persons without a disability of 61.8 percent. Despite enormous evidence that people with disabilities can work and want to work, including those with significant disabilities, our country remains entrenched in outdated and ineffective models of day services (i.e., sheltered workshops, non-work day programs) and 
precious public dollars continue to be used for these services that congregate and segregate individuals, pay subminimum wages, and deny individuals their human and civil rights.

Fortunately, a national movement is underway in the United States to challenge our service delivery system and shift our approach to competitive integrated employment. The movement, known as Employment First, prioritizes employment as the first and preferred outcome in the provision of publicly funded services for all working age individuals with disabilities, regardless of the level of disability (https://apse.org/employment-first/). The National APSE Association has taken a leadership role in advancing Employment First. According to the APSE website (www.apse.org), features of Employment First include:

- Individuals with disabilities are employed within the general workforce, regardless of the severity of disability and assistance required.

- There are measurable increases in employment of individuals with disabilities within the general workforce, earning minimum wage or higher with benefits.

- Funding is sufficient so that quality services and supports are available as needed for long-term employment success.

- Individuals with disabilities have increased incomes, financial assets, and economic wealth.

- Individuals with disabilities have greater opportunities to advance in their careers by taking full advantage of their individual strengths and talents.

- Employers universally view individuals with disabilities as an integral part of their workforce, and include people with disabilities within general recruitment and hiring efforts as standard practice.

- Young people with disabilities obtain work experiences that are typical of other teenagers and young adults.

- Greater opportunities exist for individuals with disabilities to pursue self-employment and the development of microenterprises.

- A decision not to consider employment in the community for an individual is re-evaluated on a regular basis; the reasons and rationale for this decision are fully documented and addressed in service provision.

As of April 2019, 39 states have an official Employment First policy (based on legislation, policy directive, etc.). Of these, 21 states have passed legislation stating that integrated employment is preferred over other service options. The other 18 states have a policy directive, executive order, or similar official policy statement, but not legislation. At least seven states have both legislation and a non-legislative policy directive.

\subsection{Indiana's employment outcomes}

Hoosiers with disabilities have the highest unemployment rate of any minority in Indiana. According to the National Survey of State IDD Agency Day and Employment Services, of individuals who received a day or employment service funded or monitored by the state IDD agency in 2018 , a mere $13 \%$ participated in integrated employment services compared to $21 \%$ nationally, and only $3.7 \%$ of the total state funding was used for integrated employment services, compared to $11.6 \%$ nationally. As of 2016, Indiana ranked 11th from the bottom in our rate of integrated employment for individuals with intellectual and developmental disabilities, as reported by the state to the Institute on Community Inclusion. Clearly, there is a need for systems change in Indiana, which led to efforts by IN-APSE and other advocates to pass Employment First legislation.

\section{Indiana's Employment First law and framework for change}

Thanks to the hard work of strong advocates and two excellent co-sponsors, Indiana's Employment First law was passed in 2017. It states that employment in the community is the first and preferred outcome of services for Hoosiers with disabilities. The Employment First legislation defined competitive, integrated employment or self-employment to include the following features:

- Employees with disabilities are included on the payroll of a competitive business or industry (unless self-employed);

- Individuals receives minimum or prevailing wages and benefits consistent with others in the workplace; and

- There are natural opportunities for integration and interactions with co-workers without disabilities, with customers, and/or the general public. 
The legislation mandated that the Indiana Commission on Rehabilitative Services develop a state Employment First Plan for advancing competitive, integrated employment as the first and preferred option. The law required this plan include:

- Identification of barriers to employment for individuals with disabilities (systemic, workplace, and societal/attitudinal barriers);

- An analysis of federal, state, and local agency policies concerning the provision of services to individuals with disabilities, including the impact of those policies on opportunities for competitive integrated employment; and

- Recommendations to advance competitive integrated employment for individuals with disabilities.

The Commission established an Employment First task force comprised of people with disabilities, service providers, state agency staff, advocates, and family members. In order to maximize input from people with disabilities and their families, the authors submitted a grant proposal to the Indiana Governor's Council for People with Disabilities, and were funded to roll out a statewide Employment First initiative, based at Indiana University-Purdue University, Indianapolis (IUPUI).

When designing our initiative, our framework for widespread and sustainable systems change had to include both "top-down", and "bottom-up" support from individuals with disabilities and families, service providers, employers, and other advocates. States that have been effective in their efforts to promote systems change include the following four components:

- Laws, philosophy, policies, funding, and procedures that are aligned and focused on the desired outcomes;

- Statewide capacity building, including strong and consistent leadership in key positions, training and technical assistance to shift practices, and ongoing information dissemination to inform and provide resources;

- Data-based decision making to track outcomes (i.e., increasing the number of people in competitive, integrated employment while concurrently reducing the numbers in sheltered and non-work programs); and

- Support for state and local leaders and advocates who are implementing effective changes.

\subsection{Phase I (Year 1): Building a grassroots coalition of individuals with disabilities}

Our Phase I (Year 1) activities were focused on building a grassroots coalition of self-advocates throughout the state, and to disseminate information about the Employment First legislation and the status of employment for adults with disabilities in Indiana. In addition, we formed an Advisory Committee comprised of individuals with disabilities, key state advocacy organization leaders, and state agency representatives to provide guidance throughout our initiative.

We worked with local self-advocates to host 11 Town Hall meetings in cities across the state. Team leaders with disabilities designed and led their local Town Hall gathering. In addition to sharing information about the 2017 Employment First Legislation and state Employment First Task Force, speakers with disabilities shared employment success stories and attendees engaged in table discussions focused on solutions to employment barriers and local priorities. Many of the self-advocates who attended reported they were not aware of Employment First or the passing of the law in Indiana. Over 400 participants attended the 11 Town Hall meetings and joined the Employment First Coalition.

We gathered and synthesized the recommendations that were generated at the Town Hall round table discussions. The themes that emerged were:

- Ensure competitive, integrated employment is the first and preferred outcome of publicly funded services in Indiana.

- Develop comprehensive, accessible, affordable, and reliable transportation options for individuals with disabilities.

- Increase employment of, and reasonable accommodations for, people with disabilities in Indiana workplaces through employer education and partnerships.

- Collect and share service provider employment outcomes for the individuals they serve.

- Invest in school to adult life transition services and track student employment outcomes.

- Expand knowledge of all who work with individuals with disabilities about work incentives available through public assistance programs.

After the Town Halls were completed, Team Leaders formed local teams and developed action plans to advance employment outcomes. The authors began holding monthly meetings with the Team Leaders 
to share local updates and activities and obtain their input on important state policy issues.

Additional Year 1 activities included: sharing Town Hall results with the state Employment First Task Force, conducting multiple national, state, and local presentations about our Employment First legislation and coalition, and partnering with IN-APSE to expand the Employment First section of their website.

During that first year, the project staff worked with the Team Leaders, Advisory Council, business leaders, and consultants to re-brand the initiative. They chose the name "Work to Include" to encompass the initiative's focus on disability inclusion and local teamwork to change communities.

\subsection{Phase II (Year 2): Imagining the possibilities and building business partnerships}

Our Phase II plan kicked off Year 2 with an Employment First Summit, which was a one day gathering of our Team Leaders, state agency leaders, advocacy organization representatives, service providers, and other advocates. In addition to reviewing the Employment First Legislation and activities of our Work to Include Coalition the agenda included speakers from Ohio's and Michigan's Employment First Initiative, who shared information about their plans, funding, and activities. State agency leaders provided updates about their efforts to increase employment outcomes. This allowed participants to think beyond what was in Indiana to what could happen with funding and resources for Employment First plan implementation. Finally, round table groups discussed the information shared by the speakers and generated recommendations for systems change activities to address employment barriers. Key takeaways included:

- Funding is needed to support capacity building, training, technical assistance, data collection, and dissemination.

- The state Department of Transportation should be involved in planning for accessible, affordable, and reliable transportation options.

- Everyone receiving services must have an employment goal that drives planning.

- Individual and family engagement and outreach is a critical component.

- Building business networks and educating employers has substantial impact.

- Organizations transitioning from facility-based services require support from state agencies.
Phase II also involved employer outreach, education, and partnerships. Local teams and Coalition leaders partnered with their local Chambers of Commerce, Society for Human Resource Management Chapters (SHRM), and local/state businesses to share information, conduct presentations, and collaborate on joint efforts to advance hiring of people with disabilities. As part of this effort, individuals with disabilities and employers came together to develop an Employer Toolkit. As a result, they identified and began work on a series of 11 Fact Sheets related to hiring and accommodating employees with disabilities. Team Leaders were instrumental in writing and evaluating the Employer Toolkit components, emphasizing the value of talent with disabilities in the workplace. Along with the newly developed Work to Include website and awareness campaign materials, the Employer Toolkit was timed to coincide with National Disability Employment Awareness month in October.

\subsubsection{State as Model Employer (SAME)}

Year 2 activities also involved collaboration with the Governor's office and the State Personnel Department to work toward our state as a model employer (SAME). As a model employer, the state would increase their hiring of people with disabilities in order to create a more diverse and talented workforce. This effort involved drafting an Executive Order for the governor to sign, collaborating with the head of Diversity and Inclusion in the State Personnel Department to advance their hiring and support practices, and conducting Lunch and Learn professional development workshops with state HR Managers. We were fortunate to have the assistance of a subject matter expert affiliated with the U.S. Department of Labor, Office of Disability Employment Policy (ODEP) VOICE grant as a consultant during these activities.

\subsubsection{Social media campaign}

As part of the statewide outreach campaign to share information and resources, the Work to Include Coalition used social media, including Facebook, Instagram (worktoinclude), and Twitter (@worktoinclude), as well as a monthly e-newsletter. By connecting to Town Hall participants, self-advocacy groups and others we were able to expand outreach beyond our initial efforts to hundreds more individuals with disabilities and advocates. 


\subsection{State employment first plan adoption}

The Indiana Commission on Rehabilitation Services adopted the state Employment First plan in September 2020. The Employment First Task Force, mentioned previously, had worked for months analyzing data, outlining the barriers to employment, and developing initial recommendations. The Commission invited the Work to Include Coalition to provide input based on recommendations gathered from the 11 Town Halls meetings. The Indiana Rehabilitation Services Commission then finalized the plan and gathered additional input from individuals with disabilities, service providers, state agencies and other advocates.

The Commission developed six main focus areas for action, with a vision for each area in order to set long-term goals and clearly define strategies. They are:

1. Collecting data to benchmark current performance and measure progress. VISION: Indiana has the information needed to evaluate progress toward competitive, integrated employment.

2. Finding and supporting employers to hire individuals with disabilities. VISION: Employers have a positive attitude about seeking and hiring individuals with disabilities, know the benefits of an inclusive workforce, and utilize supports when needed.

3. Promoting effective school-to-careers transition. VISION: Transition services in schools support youth to prepare for life after high school and access services so that they leave school employed or enrolled in postsecondary or career technical education.

4. Aligning government policies and funding to promote employment outcomes. VISION: State and local government policies and funding incentivize competitive, integrated employment and self-employment for individuals with disabilities, including those with significant support needs.

5. Developing quality employment services and supports for competitive employment. VISION: Individuals with disabilities, including those with the most significant support needs, have access to technology, innovative employment services and other assistance they need for competitive, integrated employment and selfemployment.
6. Creating high expectations and economic self-sufficiency among individuals with disabilities. VISION: Encouraged by their families and communities, individuals with disabilities expect to work, have access to reliable transportation and understand how to navigate work incentives.

As the Commission was finalizing its plan, Work to Include began the work of implementation and this became the focus of Phase III of our initiative.

\subsection{Phase III (Year 3) and beyond}

Our third year, or Phase III, of the initiative began with the launch of our new Work to Include website: www.worktoinclude.org where readers can access the Employer Toolkit and other materials. A major activity involved working with a marketing firm to develop materials for our October Disability Employment Awareness Month campaign. Again, taking a community level approach to outreach, local Work to Include teams planned campaign activities and submitted mini grant proposals for funding to cover the costs of their activities, which included public service announcements on radio and television, billboards, virtual job fairs (during the pandemic), information packets distributed to employers, presentations, social media and more. Several communities were able to augment their campaigns through local funding from sources like United Way, Chambers of Commerce and Community Foundations. There were six community campaigns which leveraged over $\$ 17,000$. While we continue to gather data on outcomes, we know that thousands of Hoosier businesses and public are now more aware of resources.

As noted above, the major focus of Phase III is the implementation of the Employment First plan and true systems change activities. Per the goals, these include the development of a cross-agency data collection system in order to prepare an annual Report Card. We have secured the assistance of an external expert to consult on the design of this system.

In an effort to establish a staffed state office or entity to lead the implementation of Employment First, the Work to Include Coalition linked arms with the major disability advocacy groups in the state (Self-Advocates of Indiana, the Arc, Independent Living Center Association, Rehabilitation organization, and Indiana Disability Rights (Protection \& Advocacy) to develop a strategy for securing such a state office and leadership. Meetings with state Devel- 
opmental Disabilities, Vocational Rehabilitation, and Workforce Development continue as this article is being written.

Our hopes are that we can secure the Executive Order from the governor this year, which will strengthen the implementation of the Employment First plan, establish Indiana as a model employer and, ultimately, improve employment outcomes. With the impact of the pandemic on employment of people with disabilities, the need for and timing of our governor's leadership and support could not be greater.

Plans are underway for expanding our statewide grassroots advocacy led by individuals with disabilities and family members. Supports for local teams is critical to sustain their efforts. Our Year 3 plan includes the addition of another local team in an area of the state that is currently not well represented.

Phase III also involves the continuation and expansion of outreach and information dissemination efforts via the social media outlets discussed above, our e-newsletter, webinars, presentations, and materials development, including videotaped interviews and success stories posted on our website.

Finally, Year 3 will conclude with the next Work to Include Summit. Once again, we will invite one or more leaders from other states that are farther ahead of us in their efforts and outcomes, and we will ask state leaders to provide an update about their efforts to implement the Employment First plan. As always, individuals with disabilities will be front and center when planning and conducting this summit.

\section{Conclusion}

Systems change can and must be accomplished in order to shift our outdated, segregated, and discriminatory vocational service delivery system in Indiana and across the United States. Effective and sustainable change must involve both a "top down" and "bottom up" effort that aligns policies, practices, and funding that result in desired outcomes. Employment First initiatives across the country prove that such change not only can be done, but, collectively, must be done now.

\section{Conflict of interest}

None to report.

\section{References}

University of Massachusetts Boston. (2020b). StateData: The national report on employment services and outcomes. Institute for Community Inclusion, University of Massachusetts Boston. www.statedata.info

University of Massachusetts Boston. (2020a). National survey of state IDD agency day and employment services. StateData. Institute for Community Inclusion, University of Massachusetts Boston. www.statedata.info

APSE. (2020). The Association of People Supporting Employment First (APSE). www.apse.org

U.S. Bureau of Labor Statistics. (2021, February 24). U.S. Department of Labor news release. USDL-21-0316. www.bls.gov/cps 